Beatriz Andrade do Patrocínio

\title{
A Institucionalização da Responsabilidade Social Corporativa na Indústria Farmacêutica
}

Dissertação apresentada ao Programa de Pósgraduação em Administração de Empresas da PUC - Rio como requisito parcial para obtenção do título de Mestre em Administração de Empresas

Orientador: Prof. Marcos Cohen 
Beatriz Andrade do Patrocínio

\section{A institucionalização da responsabilidade social corporativa na indústria farmacêutica}

Dissertação apresentada como requisito parcial para obtenção do grau de Mestre pelo Programa de Pós-graduação em Administração de Empresas da PUC-Rio. Aprovada pela Comissão Examinadora abaixo assinada.

Prof. Marcos Cohen

Orientador

Departamento de Administração - PUC-Rio

Profa ${ }^{a}$. Patrícia Amélia Tomei Departamento de Administração - PUC-Rio

Prof. José Luis Felício dos Santos de Carvalho

UFRJ

Profa. Mônica Herz

Vice-Decana de Pós-Graduação do CCS

Rio de Janeiro, 22 de agosto de 2011 
Todos os direitos reservados. É proibida a reprodução total ou parcial do trabalho sem autorização da universidade, da autora e do orientador.

\section{Beatriz Andrade do Patrocínio}

Graduou-se em Administração na Universidade Federal do Rio de Janeiro (UFRJ) em 2006. Atuou três anos na área de Consultoria em Gestão de Riscos da empresa Deloitte e desde 2010 trabalha na Petrobras na Área Internacional.

Ficha Catalográfica

Patrocínio, Beatriz Andrade do

A institucionalização da responsabilidade social corporativa na indústria farmacêutica / Beatriz Andrade do Patrocínio; orientador: Marcos Cohen. - 2011. $156 \mathrm{f} . ; 30 \mathrm{~cm}$

Dissertação (mestrado) - Pontifícia Universidade Católica do Rio de Janeiro, Departamento de Administração, 2011. Inclui bibliografia

1. Administração - Teses. 2. Responsabilidade social corporativa. 3. Teoria institucional. 4. Indústria farmacêutica. I. Cohen, Marcos. II. Pontifícia Universidade Católica do Rio de Janeiro. Departamento de Administração. III. Título. 
Àqueles que tiveram a vida transformada por projetos sociais 


\section{Agradecimentos}

A Capes e à PUC - Rio, pelos auxílios concedidos, imprescindíveis para a realização deste trabalho.

Ao meu orientador Professor Marcos Cohen pela parceria na realização deste trabalho.

A Maria Teresa Campos, secretária de pós-graduação do IAG, por sua ajuda que foi essencial para que eu pudesse avançar nos meus objetivos acadêmicos.

Ao Professor José Luis Felício dos Santos de Carvalho pela força e estímulo aos estudos que ultrapassou a graduação.

Aos profissionais das empresas e projetos sociais analisados que contribuíram para esta pesquisa ao disponibilizarem parte de seu precioso tempo de trabalho.

A minha mãe Cléa e meu pai Jorge que como professores sempre me ensinaram a importância do estudo.

Ao Rafael por compreender minha ansiedade, cansaço e minha pesada carga horária de estudos.

Aos meus amigos do mestrado que tornaram os momentos de estudo mais leves e felizes. 


\section{Resumo}

Patrocínio, Beatriz Andrade do; Cohen, Marcos. A institucionalização da responsabilidade social corporativa na indústria farmacêutica. Rio de Janeiro, 2011. 156p. Dissertação de Mestrado - Departamento de Administração, Pontifícia Universidade Católica do Rio de Janeiro.

A responsabilidade social corporativa é um tema de bastante destaque atualmente. Para as empresas, investir em ações socialmente responsáveis tem se tornado essencial visto que o investimento pode resultar em melhoria da imagem corporativa, vantagem competitiva e retornos financeiros, além de conferir legitimidade à organização. $\mathrm{O}$ conceito de responsabilidade social corporativa abrange as relações da organização com seus stakeholders e as ações ocorrem em diversas áreas, sendo a área social a que mais se destaca no Brasil. O objetivo desta dissertação é compreender, como tem ocorrido a institucionalização da responsabilidade social corporativa em empresas farmacêuticas e os impactos e as consequências deste processo nas comunidades alcançadas pelos projetos sociais realizados por essas empresas. Para isto foi feita uma revisão da literatura sobre responsabilidade social corporativa, teoria dos stakeholders e teoria institucional e uma pesquisa qualitativa e descritiva. Foi realizada pesquisa documental, entrevistas, aplicação de questionários e elaborados estudos de caso de quatro empresas farmacêuticas. Os dados coletados foram submetidos à análise de conteúdo e posterior triangulação. Os resultados desta análise sugerem que a responsabilidade social corporativa nas empresas farmacêuticas estudadas está caminhando para um estágio de total institucionalização com algumas características ainda do estágio institucional. Além disso, a evolução da responsabilidade social corporativa e sua institucionalização nestas empresas têm tido impactos positivos nas comunidades no entorno, pois são realizados trabalhos sociais bem estruturados e cujos resultados são satisfatórios e distanciam-se do simples assistencialismo.

\section{Palavras-chave}

Responsabilidade social corporativa; teoria institucional; indústrias farmacêuticas. 


\section{Abstract}

Patrocínio, Beatriz Andrade do; Cohen, Marcos (Advisor). The institutionalization of corporate social responsibility in the pharmaceutical industry. Rio de Janeiro, 2011. 156p. MSc. Dissertation Departamento de Administração, Pontifícia Universidade Católica do Rio de Janeiro.

Corporate social responsibility is a very prominent subject nowadays. For companies, investing in socially responsible actions has become essential since this kind of investment can result in a better corporate image, competitive advantage and financial returns. Moreover it legitimates the organization. The concept of corporate social responsibility includes the organization's relationship with its stakeholders and the action occurs in several areas, being the social area the one that stands out in Brazil. The purpose of this dissertation is to understand how has been occurring the corporate social responsibility institutionalization in the pharmaceutical companies and the impacts and consequences of this process to the communities reached by the social projects undertaken by those companies. A literature review about corporate social responsibility, stakeholder theory and institutional theory was conducted along with a qualitative and exploratory research. Documentary research was conducted and interviews, questionnaires and case studies were prepared about four pharmaceutical companies. The collected data were submitted to content analysis and subsequent triangulation. The results suggest that corporate social responsibility in considered pharmaceutical companies is moving to a stage of full institutionalization with some features of the institutional stage. Besides, the evolution of corporate social responsibility and its institutionalization in these companies have shown positive impacts on communities due to well-structured social actions performed. The results are satisfactory and different from simple philanthropy.

\section{Keywords} industry

Corporate social responsibility; institutional theory; pharmaceutical 


\section{Sumário}

1 . Introdução 14

1.1. Objetivos da pesquisa 16

1.2. Delimitação do estudo 16

$\begin{array}{ll}\text { 1.3. Relevância do estudo } & 18\end{array}$

2. Referencial teórico 20

2.1. Responsabilidade social corporativa 20

2.1.1. Uma análise preliminar do tema 20

2.1.2. Responsabilidade social corporativa: definições e motivações 23

2.1.3. Responsabilidade social corporativa e ética 25

2.1.4. Modelos e abordagens de responsabilidade social corporativa 27

2.1.5. Indicadores de responsabilidade social corporativa 31

2.2. Teoria institucional e legitimidade 32

2.2.1. A teoria institucional e o processo de institucionalização 32

2.2.2. Estágios de institucionalização de Tolbert e Zucker 36

2.2.3. A institucionalização da responsabilidade social corporativa 41

2.2.4. Isomorfismo e legitimidade 43

2.3. Teoria dos stakeholders 45

2.3.1. Teoria dos stakeholders: conceitos e definições 45

2.3.2. Críticas à teoria dos stakeholders 46

2.3.3. Classificação dos stakeholders 48

2.3.4. Teoria dos stakeholders e responsabilidade social corporativa $\quad 48$

3. Metodologia 51

3.1. Tipo de pesquisa 51

3.2. Seleção de empresas e respondentes 52

3.3. Coleta de dados 53

3.3.1. Pesquisa bibliográfica 54

3.3.2. Pesquisa documental 55

3.3.3. Levantamentos de percepções por meio de entrevistas 55 
3.3.3.1. Roteiro de entrevistas nas empresas

3.3.4. Levantamento de percepções de parceiros 59

3.3.4.1. Roteiro de questionários para os parceiros $\quad 59$

3.4. Análise e tratamento dos dados 60

3.5. Limitações do método 64

4. Características e resultados dos casos estudados 65

4.1. A indústria farmacêutica 66

4.1.1. A indústria farmacêutica no mundo 66

4.1.2. A indústria farmacêutica no Brasil 69

4.1.3. A indústria farmacêutica e a responsabilidade social corporativa 73

4.2. Caso 1 - Merck 75

4.2.1. Aspectos gerais 75

4.2.2. Institucionalização da responsabilidade social corporativa $\quad 78$

4.2.2.1. Dimensão processos 78

4.2.2.2. Dimensão característica do adotante 81

4.2.2.3. Dimensão ímpeto para difusão 82

4.2.2.4. Dimensão atividade de teorização 83

4.2.2.5. Dimensão variância na implementação 84

4.2.2.6. Dimensão taxa de fracasso estrutural 85

4.2.2.7. Resumo 86

4.2.3. Responsabilidade social corporativa e impactos na comunidade 88

4.3. Caso 2 - Farmanguinhos 90

4.3.1. Aspectos gerais 90

4.3.2. Institucionalização da responsabilidade social corporativa 93

4.3.2.1. Dimensão processos 93

4.3.2.2. Dimensão característica do adotante 95

4.3.2.3. Dimensão ímpeto para a difusão 97

4.3.2.4. Dimensão atividade de teorização 98

4.3.2.5. Dimensão variância na implementação 99

4.3.2.6. Dimensão taxa de fracasso estrutural 100

4.3.2.7. Resumo 100

4.3.3. Responsabilidade social corporativa e impactos na comunidade 102 
4.4. Caso 3 - B.Braun 105

4.4.1. Aspectos gerais 105

4.4.2. Institucionalização da responsabilidade social corporativa 107

$\begin{array}{ll}\text { 4.4.2.1. Dimensão processos } & 107\end{array}$

4.4.2.2. Dimensão característica do adotante 110

4.4.2.3. Dimensão ímpeto para difusão 111

4.4.2.4. Dimensão atividade de teorização 112

4.4.2.5. Dimensão variância na implementação 113

4.4.2.6. Dimensão taxa de fracasso estrutural 114

$\begin{array}{lr}\text { 4.4.2.7. Resumo } & 114\end{array}$

4.4.3. Responsabilidade social corporativa e impactos na comunidade 116

4.5. Caso 4 - Empresa X 120

4.5.1. Aspectos gerais 120

4.5.2. Institucionalização da responsabilidade social corporativa 122

4.5.2.1. Dimensão processos 123

4.5.2.2. Dimensão característica do adotante 125

$\begin{array}{ll}\text { 4.5.2.3. Dimensão ímpeto para a difusão } & 127\end{array}$

4.5.2.4. Dimensão atividade de teorização 128

4.5.2.5. Dimensão variância na implementação 129

4.5.2.6. Dimensão taxa de fracasso estrutural 129

4.5.2.7. Resumo 130

4.5.3. Responsabilidade social corporativa e impactos na comunidade 132

5. Análise conjunta dos casos 136

6 . Conclusões 143

$\begin{array}{lr}\text { 7. Referências bibliográficas } & 148\end{array}$ 


\section{Lista de figuras}

Figura 1 - Pirâmide da responsabilidade social corporativa 28

Figura 2 - Processos inerentes à institucionalização 38

Figura 3 - Modelo da doutrina dos stakeholders 45

Figura 4 - Fluxo da pesquisa 63 


\section{Lista de quadros}

Quadro 1 - Os três pilares das instituições 35

Quadro 2 - Estágios de institucionalização e dimensões comparativas 40

Quadro 3 - Efeitos das ações de responsabilidade social corporativa conforme o stakeholder envolvido 49

Quadro 4 - Roteiro para as entrevistas nas empresas $\quad 57$

Quadro 5 - Perguntas aplicadas a parceiros em projetos sociais $\quad 59$

Quadro 6 - Características relacionadas às dimensões propostas por Tolbert e Zucker (1999) 66

Quadro 7 - Classificação das dimensões comparativas 86

Quadro 8 - Direcionamento da Merck para os estágios de institucionalização de Tolbert e Zucker (1999) 87

Quadro 9 - Classificação das dimensões comparativas 101

Quadro 10 - Direcionamento de Farmanguinhos para os estágios de institucionalização de Tolbert e Zucker (1999) 102

Quadro 11 - Classificação das dimensões comparativas 115

Quadro 12 - Direcionamento da B.Braun para os estágios de institucionalização de Tolbert e Zucker (1999) 116

Quadro 13 - Classificação das dimensões comparativas 131

Quadro 14 - Direcionamento da Empresa X para os estágios de institucionalização de Tolbert e Zucker (1999)

Quadro 15 - Resumo da institucionalização da responsabilidade social corporativa nas empresas estudadas 


\section{Lista de tabelas}

Tabela 1 - Maiores empresas farmacêuticas no mundo - 2008 68

Tabela 2 - Ranking IMS setor farmacêutico brasileiro - market share 69 